\title{
Impact of Justices, Training, and Co-Ordination on Government Employees' Job Satisfaction: A Case of Pakistan
}

\author{
Syed Mudasser Abbas' ${ }^{1}$, Fahad Asmi2 ${ }^{*}$, Muhammad Salman Ahmad ${ }^{2}$, Madad Ali² \\ ${ }^{1}$ Kohat University of Science \& Technology, Kohat, Pakistan \\ ${ }^{2}$ School of Public Affairs, University of Science and Technology of China, Hefei, China \\ Email: fasmie@mail.ustc.edu.cn
}

How to cite this paper: Abbas, S.M., Asmi, F., Ahmad, M.S. and Ali, M. (2017) Impact of Justices, Training, and Co-Ordination on Government Employees' Job Satisfaction: A Case of Pakistan. Journal of Human Resource and Sustainability Studies, 5, 179-192. https://doi.org/10.4236/jhrss.2017.53017

Received: August 17, 2017

Accepted: September 24, 2017

Published: September 27, 2017

Copyright (C) 2017 by authors and Scientific Research Publishing Inc. This work is licensed under the Creative Commons Attribution International License (CC BY 4.0)

http://creativecommons.org/licenses/by/4.0/

(c) (i) Open Access

\begin{abstract}
This research seeks to investigate the influence of different public sector organizational antecedents on government employees' job satisfaction. Extensive reviews of literature revealed perceived procedural justice, distributive justice, esprit de corps and job training as the most referred antecedents of employees' job satisfaction. To empirically test the study hypotheses, data were collected from 332 personnel working in National Savings (Public sector investment bank in Pakistan). Structural Equation Modeling (SEM) was used to analyze the data using SPSS Statistics 23 and AMOS 21. The results of this research generally support the hypothesis proposing the relationships between organizational antecedents (procedural and organizational justice and esprit de corps) and job satisfaction, except the association between employee's training and job satisfaction. The study helps in formulating policies regarding workforce and labor management by providing in-depth insight to the concerned authorities of various government organizations. This research, in addition to limitations, provides some tangible future research directions for future researchers in the light of its findings.
\end{abstract}

\section{Keywords}

Distributive Justice, Procedural Justice, Job Training, Job Satisfaction, Esprit de Corps, Public Sector Institutions

\section{Introduction}

In the field of human resource development, job satisfaction has been given significance importance, especially in the case of public sector institutes. It can be measured form employees' satisfaction for extrinsic and intrinsic job features. 
In-depth analysis of literature presents various theories explaining the concept of job satisfaction. Maslow's hierarchy of needs, one of the most important theories, explains men's needs in hierarchical order ranging from psychology to self-actualization. Several scholars such as Kuhlen [1] and Conrad [2] making Maslow's theory as a base, professed to measure employees' satisfaction through their pleasure. From another perspective, an association was found about job satisfaction with the views of Hertzberg and Mausner [3]. Some of the extrinsic and intrinsic factors, in the light of above theories, including achievement, pay, work environment, accountability and interpersonal relationships may be incorporated as a reason of workers' behaviors at companies in addition to turnover and performance. However, an increasing trend has been observed among employees regarding job turnover resultant of several factors [4]. This research, based on above discussions, is an attempt to understand the antecedents of job satisfaction of employees. Moynihan and Pandey in their work stated that culture has a significant role in job satisfaction in public sector institutes [5]. This is because of the fact that satisfaction is the phenomena related to human psychology and is influenced by cultural behavioral patterns. The antecedents of job satisfaction and the general attitude of individual to word the job, therefore vary from culture to culture. This study therefore attempts to investigate the above mentioned concepts from the Pakistani public sector culture perspective. The section below, gives in-depth understanding of various antecedents of employees' job satisfaction.

\section{Literature Review}

Many scholars studied the effect of various organizational antecedents on job satisfaction. Schmiat in his work found close correlation between organizational schooling and workers training [4]. In the same way, Lusch, Boyts and Naylor found a positive role of professionalism on job satisfaction [6]. McAuliffe, Manafa, Bowie and White in their work, found organizational justice to be the main contributor to workers' job contentment [7]. This research aims at understanding synergic effect of antecedents on job satisfaction as stretched by previously related studies [8]. This research, in particular, is an attempt to understand various job satisfaction models. It further attempts observe its relationship among organizational justice, Esprit de corps, training and job satisfaction. They further state that satisfaction of the employees on job vary from culture to culture, hence this study attempts to study the influence of Organizational antecedents on employees' job contentment which are discussed in subsequent section.

\subsection{Organizational Justice}

Greenberg and Konovsky in their research divided organizational justices into procedural and distributive justice [9] [10]. Procedural justice is the noticeable impartiality of practices in the company like job involvement and fair supervision. Greenberg in his research defined distributive justices as an apparent 
equality in pay distribution and job satisfaction appraisal system [9].

\subsubsection{Perceived Procedural Justice}

Framer and Greenberg in their work associated procedural fairness with decisions employment outcomes [9] [11]. It is the accuracy in procedures in company's decisions [12]. Lambert in this work describes impartiality as an important component of organizational environment and employment. Review of the above literature support the implication of impartial procedural processes with regard to management of any company [13]. Greenber stressed in giving as much importance to the process of the outcomes as that of the results itself [14].

Lambert in this work found a strong positive correlation between procedural fairness and workers' job contentment [13]. In one similar study, Dailey and Haq argued on the importance of procedural justice for employee motivation [15]. They also found it to be the main factor in employee retention and satisfaction. The absence of such practices, according to the author, leads to employees' dissatisfaction and increased turnover.

Similarly, several other studies have been carried out to understand the workers' satisfaction. Folger and Konovsky in their research observed job satisfaction as a consequence of procedural justice [16]. In one similar study, Huo and Macfalin studied the government organization for analyzing the impact of procedural fairness on employees' job contentment [17] [18]. Workers' perception about job satisfaction, workplace impartialities and motivation are given more preference in highly professional organizations. The above discussion can be used for hypothesis (H1) regarding positive association between job satisfaction and procedural justice.

H1: Positive "Procedural Justice" (PJ) has certain and notable effect on employee Job Satisfaction (SAT).

\subsubsection{Perceived Distributive Justice}

Adams first coined the idea of distributive justice [19]. According to him, the fairness and unfairness of any process is justified by employees by comparison of their inputs (efforts and time) and outputs (status and compensation) with co-workers. A favorable value results in lament, embarrassment and culpability for the reason of being over obliged but in opposite circumstances employees will result in resentment and abhorrence. Variations in productivity and satisfaction, as a result of such comparative results, have been found to affect employees' turnover [20]. So, on the basis of equity theory, distributive justice has been professed to have positive relationship with worker's satisfaction and motivation. Under the literature context, the hypothesis (H3) will be as following:

H3: Positive "Distributive Justice" (DJ) certainly and notably effect on employee job Satisfaction (SAT).

\subsection{Job Training}

In this era of global competition, career advancement is subject to self-management 
and availability of learning opportunities. Nowadays, especially in public sector organizations, employees' behavior and attitude towards job satisfaction is worldwide recognized matter. Schmidt, in is research suggested workplace training as an important predictor of positive attitude of employees [4].

Landy, defined job training as set of properly sequenced activities aligned with organizational goal which focuses on employee's participation which results in increasing and pushing upwards the abilities, knowledge, comprehension and expertise of the employees [21]. A study conducted by Georgellis describe job training as the openness and ease of access of the employees to involve their selves in diverse activities such as written possessions for acquiring learning different activities, and availing short courses opportunities, as well as participating in different discussion groups, seminars and workshops in different and diverse organizations [22]. Although, job training has been considered as important predictor of job satisfaction yet considerable importance has not been given.

The study of literature highlighted several authors professing the positive association between training of the employees on job and their satisfaction level. The lack of access to job training is one of the prominent causes of worker's dissatisfaction [23]. In one similar research done by Shields and Wheatley taking the sample of nurses for hospitals of United Kingdom, a strong correlation was observed between availability of training opportunities and employees' job satisfaction [24]. Several other researchers like Tanja, Gazioglu and Jones also found positive association between employees' training and job satisfaction [25] [26] [27].

Blum in his research found significant correlation between acquisition of new skills and worker's satisfaction [28]. The importance of job training can be understood by studying above mentioned literature. It can leverage the workforce in exploring various aspects of job performance. Siddiqui in his research, using doctors as research participants for Pakistani hospitals, stress on training programs for updating the skill inventory [29].

In one similar research Haq examined the workplace stress among the employees in the department of health [15]. The research examined association between work stress and lack of training opportunities. The training was considered to be one the main reason of worker's dissatisfaction. The study of above literature supports strong association between training opportunities and workplace satisfaction and classified the Hypothesis (H2) as following:

H2: Positive "Job Training" (JT) is certainly and notably effect on employee "Job Satisfaction" (SAT).

\subsection{Esprit de Corps}

In order to increase individual's capacity and involve them in team participation Esprit de corps can serve as an another additional resource. The core motive of Esprit de corps is to enhance and broadened individuals own view and ability depends on his mind-set which he possesses about the group in which he is 
about to get involved. Employees remain much conscious regarding the problems of their teammates and want to evaluate that how much the individual concern or care about the team moral and spirit [30]. Team is an association of inter-dependent individuals working collaboratively for the purpose of unified objective [31]. He further argued that team spirit and fortitude is the symphony of enthusiastically joint and mix feelings, thoughts, mind-sets and principles that people make and hold about their mates with whom they are working together.

Esprit de corps, the author explained, is of motivation for goal achievement. Defining esprit de corps in his research, William professed it to be associated with the level of commitment in organization for mutual objectives [32]. According to Homburg, it serves as vital asset for organizations mostly relying on informal settings [33].

Boyt found strong association between workers' satisfaction and team spirit [34]. He further argued that the raise in the seemingly social capital, will have a positive effect on the team spirit and motivation, which will result in a positive effect on employees' job satisfaction level working in that organization. One of the research investigation done by Hwang in which they considered a public sector hospital in South Korea, the result of that study revealed that physicians in those hospital have noted a negative impact between work group friendliness and team spirit. [35]. However, findings of the research done in Pakistan mostly reveal that prefer to work as individuals then as team.

Therefore, they give priority to individual task completion thus ignoring the importance of completion of the whole project [36]. In developing countries like Pakistan, the team work philosophy is of great corporate importance. This study attempts to test the relationship between team spirit and employees' job satisfaction in those organizations where team assignments are the mode of working as following hypothesis (H4).

H4: Positive "Esprit de Corps" (TEAM) is certainly and notably effect on employee "Job Satisfaction" (SAT).

\section{Methodology}

The methodological aspect defines and elaborates the strategic manner to achieve the objective of the study. In the purposive manner, the job satisfaction in the public sector employees is going to be reviewed in terms of the collective output of "procedural and distributive justice", "training" and the level of collaboration observe-able while performing routine tasks in the office. The collective intentions are computed in the cross sectional way in terms of time as monomethod is recorded in the current study. The quantitative approach of data collection and analysis will be followed in the current study.

\subsection{Data Profiling and Sampling Method}

The traditional offline questionnaire in the printed format distributed in the 54 branches of National Saving Bank, Pakistan to interact with the government em- 
ployees. Specifically, the network branches of National Savings in Peshawar, Hangu, Hassanabdal, Faisalabad, Lahore and Multan will be covered. The purpose to cover geographically scattered network of branches was purposefully to generalize the recorded findings to understand the employees' behavior across the country.

The structured close ended questionnaires followed as the deductive approach if research is defined to understand employees' satisfaction in public sector institutes. Conclusively, 332 responses collected in the return of 500 of the requested participants. The collection rate of response in the return was concluded as $66 \%$ of the requested participants. The challenging and more controversial observation initially collected and observed is the level of education the most of the employees have acquired, as almost $67 \%$ of the respondents only acquired 14 years of education (it includes B. Commerce and BSc Statistics and Economics).

\subsection{Instrumental Validity}

The structured questionnaire adopted on the basis of existing pool of literature discussing and elaborating the constructs in the quantitative manner. The scale items used for "Job Training" by Watt and like [37] with the items count of 4, "Job Training" by Schmidt [4] and items count of 3, "Esprit de corps" by Joworsky and colleagues [30] with the collective item count of 3 , and the procedural and distributive justice by Niehoff and Moorman [38] in the item count of 3 and 4 respectively will be accounted for the current study. The purpose to adopt existing instrumental scales is to increase the validity and reliability of the proposed study and the future findings.

The likert scale to understand the attitude and behavior of government employees was adopted where the range of 5 unit of scale is observed (1 to 5) where the 1 explains the high negative perception to the highly positive perception at 5. To increase the validity and dependency on the results, the pilot test in Peshawar only conducted where 5 only branches targeted and the sample size of 30 was collected as a pilot test. The reliability of inter item correlation mean and Cronbach alpha recorded in the desired range. Specifically, the recorded values for each of the construct observed above 0.70 are as advised by previous studies [39].

\section{Analysis}

In the quantitative studies to measure the employees' motivation, while considering the determining factors like procedural and distributive justice with the job training and team esprit is never being discussed in the case of public sector institutes of developing country like Pakistan. In the current section the reliability, validity and consistency of the results will be examined. In the later stage of examination, the Confirmatory and model fitness related tests will be performed. The statistical tools i.e. SPSS and AMOS will be adopted as its most preferred in the previous studies. 
In the descriptive manner, the initial exploratory results are shown the dominations of male in contrast of female as $76 \%$ of the respondents are male. In terms of education, most of the respondents are undergraduate as $48 \%$ respondents claimed to attend university as undergraduate level. This count is statistically followed by the respondents who have attended university at postgraduate level. Specifically, it is $28 \%$ respondents count. The further section will be discussed the internal and external reliability of the surveyed data to get the results more reliable and valid.

The CFA used to be followed after the comprehensive examination of each of the construct by using exploratory factor analysis and CFA will lead to SEM to define and examine the path analysis to understand each of the claimed hypotheses and impact of each of the determinant to formulate employees' satisfaction.

Step 1: Within each of the independent variable and to challenge each of the relationship, EFA used to examine each of the variables internally and comprehensively examine the structure of the data. The sample adequacy in the statistical manner usually followed the KMO and Bartlett test. In the current study, the 0.887 of KMO value is noted which defined and recorded in the preferred range. In the advance level significance measure, Bartlett test also returned favorable results.

Step 2: The internal by Cronbach Alpha, composite reliability, and inter item variances i.e. Average variance extracted. The detailed results for the validity and reliability tests are shared below in the table. The AVE values higher than 0.50 and CR and CA noted higher than 0.70 as recommended by the previous studies.as shown in the Table 1.

The descriptive statistics about primary findings like means and standard derivation for examining each of the construct and the discriminatory tests and examination are usually targeted to examine the correlation among latent variables. It helps to identify two or more than two constructs representing the same aspect of the employee's opinion. Moreover, the square root of AVEs for each of the construct should be higher than recorded correlation among each of the variable studied in the current study. The supportive responses from the discriminating validating tests increases the reliability of the results concluded in the study. Specifically, all the discriminating tests are supportive in the current study as mentioned in the Table 2.

The sole objective to adopt Structured Equation Modeling in the current approach of study is to analyze each of the paths in the proposed model, confirmatory evaluation of factors and fitness measures to comprehensively analyze the proposed model [40]. The list of all examined model fitness indices are discussed in the Table 3 below. The recorded CMIN is 2.306 which is lower the upper limit of 3.0 as discussed in the previous literature.

The CMIN comprised of degree of freedom and Chi-square, in the current study, the degree of freedom recorded as 109 and value of Chi-square as 251.34. The sensitivity of CMIN with the sample size is highly discussed and it raises the 
Table 1. Relibility analysis for each of the construct.

\begin{tabular}{|c|c|c|c|c|c|}
\hline Construct & $\begin{array}{c}\text { Items/ } \\
\text { Questions }\end{array}$ & $\begin{array}{l}\text { FL (Factor } \\
\text { Loadings) }\end{array}$ & $\begin{array}{l}\text { CR (Composite } \\
\text { Reliability) }\end{array}$ & $\begin{array}{c}\text { CA (Cronbach } \\
\text { Alpha) }\end{array}$ & $\begin{array}{c}\text { AVE } \\
\text { (Average Variance } \\
\text { Extracted) }\end{array}$ \\
\hline \multirow{4}{*}{$\begin{array}{l}\text { Distributive Justice } \\
\text { (DJ) }\end{array}$} & DJ1 & 0.837 & \multirow{4}{*}{0.879} & \multirow{4}{*}{0.899} & \multirow{4}{*}{0.646} \\
\hline & DJ2 & 0.809 & & & \\
\hline & DJ3 & 0.789 & & & \\
\hline & DJ4 & 0.779 & & & \\
\hline \multirow{4}{*}{ Satisfaction (SAT) } & SAT1 & 0.815 & \multirow{4}{*}{0.850} & \multirow{4}{*}{0.872} & \multirow{4}{*}{0.588} \\
\hline & SAT2 & 0.800 & & & \\
\hline & SAT3 & 0.774 & & & \\
\hline & SAT4 & 0.671 & & & \\
\hline \multirow{3}{*}{ Job Training (JT) } & JT1 & 0.886 & \multirow{3}{*}{0.823} & \multirow{3}{*}{0.895} & \multirow{3}{*}{0.611} \\
\hline & JT2 & 0.846 & & & \\
\hline & JT3 & 0.838 & & & \\
\hline \multirow{3}{*}{$\begin{array}{l}\text { Procedural Justice } \\
\text { (PJ) }\end{array}$} & PJ1 & 0.880 & \multirow{3}{*}{0.0 .873} & \multirow{3}{*}{0.840} & \multirow{3}{*}{0.697} \\
\hline & PJ2 & 0.827 & & & \\
\hline & PJ3 & 0.797 & & & \\
\hline \multirow{3}{*}{ Esprit (TEAM) } & TEAM1 & 0.828 & \multirow{3}{*}{0.847} & \multirow{3}{*}{0.833} & \multirow{3}{*}{0.650} \\
\hline & TEAM2 & 0.826 & & & \\
\hline & TEAM3 & 0.764 & & & \\
\hline
\end{tabular}

Table 2. Survey Items' Mean, Deviation in each item, Correlation and square root of AVEs.

\begin{tabular}{cccccccr}
\hline Construct & Mean & SD & DJ & SAT & JT & PJ & TEAM \\
\hline Distributive justice (DJ) & 4.48 & 0.772 & 0.803 & & & & \\
Satisfaction (SAT) & 4.37 & 0.767 & $0.565^{* *}$ & 0.766 & & & \\
Job Training (JT) & 7.32 & 0.799 & $0.441^{* *}$ & $0.474^{* *}$ & 0.781 & & \\
Procedural Justice (PJ) & 4.39 & 0.801 & $0.424^{* *}$ & $0.395^{* *}$ & $0.294^{* *}$ & 0.834 & \\
Esprit (TEAM) & 4.25 & 0.767 & $0.473^{* *}$ & $0.511^{* *}$ & $0.356^{* *}$ & $0.290^{* *}$ & 0.806 \\
\hline
\end{tabular}

${ }^{* *}=$ correlation at 0.01 level.

Table 3. Recorded indexes measured in SEM (analysis).

\begin{tabular}{ccc}
\hline Index measured & Results in Model & Recommended value \\
\hline Chisquare $\left(\mathrm{X}^{2}\right)$ & 251.345 & - \\
Degree of freedom & 109 & - \\
CMIN & 2.306 & Under 3.0 \\
GFI & 0.921 & 0.90 \\
AGFI & 0.888 & 0.80 \\
RMSEA & 0.062 & Lower than 0.80 \\
TLI & 0.948 & 0.95 \\
CFI & 0.959 & 0.95 \\
NFI & 0.930 & 0.95 \\
\hline
\end{tabular}

Recommended values by (Litze Hu \& Bentler, 1999). 
importance of fitness indices to be studied. Non-centrality indices noted with the observed value for 0.062 and 0.959 for RMSEA and CFI respectively. Absolute indices of GFI and AGFI are recorded as 0.921 and 0.888 respectively. Moreover, the value of NFI and TLI as relative indices recorded as 0.930 and 0.948 respectively. The only slightly unfavorable results recorded for NFI and TLI in the current study as recordings are slightly close to the lower limit of the recommended value of 0.95 as mentioned in the existing pool of literature before [41]. In tabular form, all the measuring indices are mentioned below in Table 3.

To measure the public sector employee's satisfaction, in the current study, four exogenous constructs considered where the satisfaction among employees classified as only endogenous variable in the current study as shown in the Figure 1.

The team esprit (TEAM) and distribute justice (DJ) concluded as the most influential factors among all exogenous factors studied in the current study. Specifically, the list of all hypotheses studied is mentioned in the Table 4.

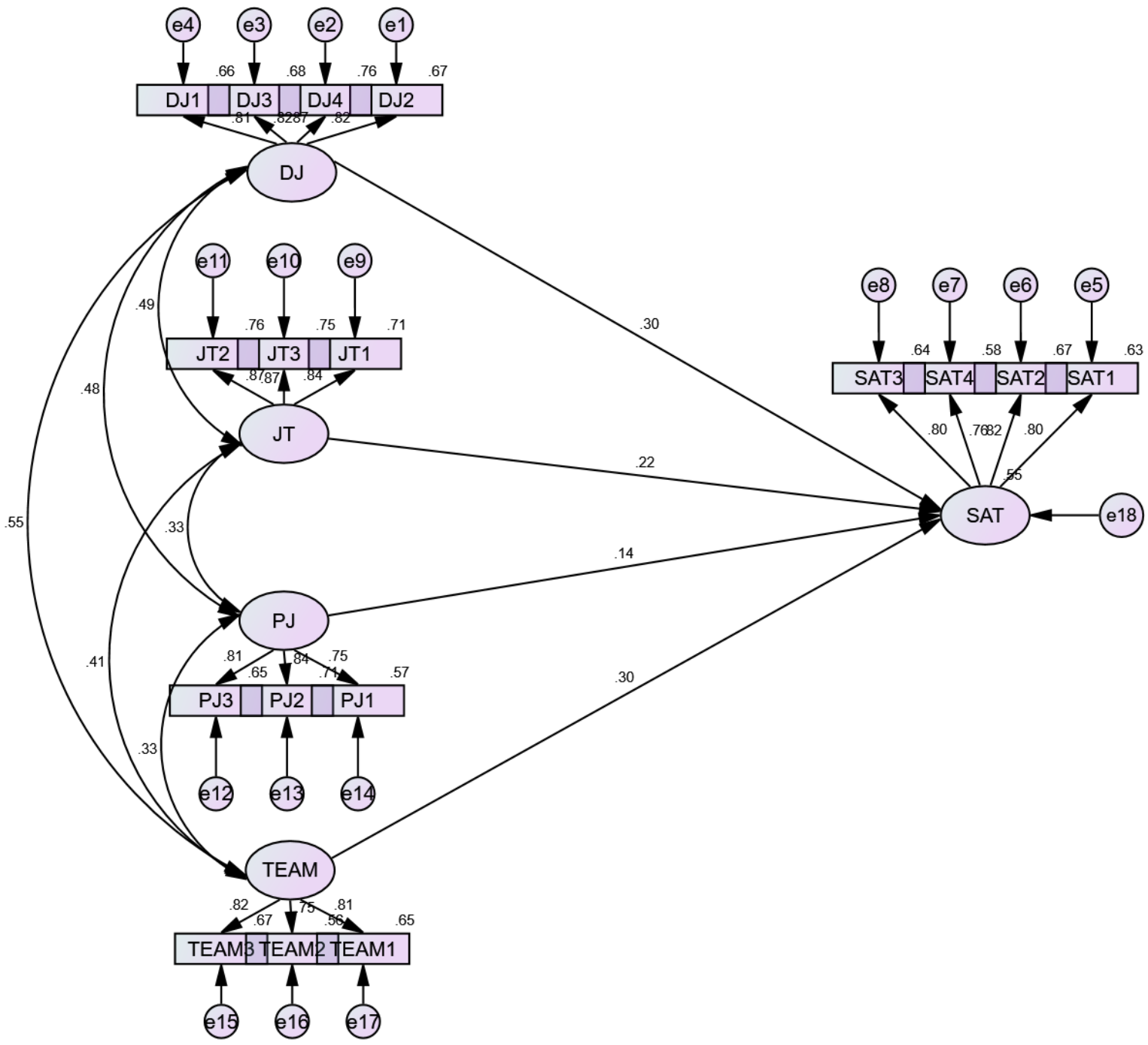

Figure 1. Path analysis of current study. 
Table 4. Evaluation and analysis of hypotheses.

\begin{tabular}{ccccc}
\hline Hypotheses & Detail & Beta $(\beta)$ & Significance & Result \\
\hline H1 & DJ+ $\rightarrow$ SAT + & 0.300 .1 & $<0.001$ & True/Valid \\
H2 & JT $+\rightarrow$ SAT + & 0.222 & $<0.001$ & True/Valid \\
H3 & PJ $\rightarrow$ SAT + & 0.141 & $<0.05$ & True/Valid \\
H4 & TEAM $+\rightarrow$ SAT + & 0.295 & $<0.001$ & True/Valid \\
\hline
\end{tabular}

All four hypotheses supported and validated in the current study. Specifically, $\mathrm{H} 1$ concluded as the strongest exogenous factor where "Distributive Justice" succeeds to define "public sectors" employee's satisfaction around 30\% among all independent factors. In statistical manner, beta value of 0.301 with the p-value $<0.001$ concluded as the most dominating independent factor. H2: The predictor of "Job training" appeared with the beta value of 0.222 with the same significance level as observed for H1 $(\mathrm{p}<0.001)$ categorized $\mathrm{H} 2$ as third most prominent independent factor in the current study. H3: In terms of significance level, $\mathrm{H} 3$ ranked the least with the $\mathrm{p}$ value of 0.013 (less than 0.05 ) and the beta value of 0.141 . It is important to mention that $\mathrm{H} 3$ is the weakest determinant in the current study. H4: It is followed by "Esprit" where team communication, understanding and harmony defined almost $29 \%$ of the current situation where beta of 0.295 with the p-value of 0.001 noted.

Findings of this research showed positive correlation between distributive justice, procedural justice and employment satisfaction. The finding seems consistent with the work of Daily and Haq [15] and Lambart [13] professing the importance of administrative impartiality in job satisfaction. The study, in line with the findings of Meral [42], found positive association between workplace satisfaction and team spirit. Astonishingly however, training of staff and procedural fairness were establishing to have less significant association with job contentment which makes the result of Shields and Wheatley [43] and many such authors encouraging.

Results of the previous researches professed a positive role training plays in job contentment. However, while deducing the new findings of this investigative study and exploring the effects of trainings related with jobs and current employees' satisfaction the constricted and more homogenous character of the sample in this study should be taken into consideration. Additionally, one of the most important tangible results of the research indicated that procedural justice emerged as weakest determinate and having less explanatory factor of employees' job satisfaction. However, it concerns and highlights are strong determinant of employee's satisfaction in the sales sector which gives much value and preference to the plainness of sales dealings such as daily sales coverage and reporting to top management, sales scheduling and other sales related reporting.

The study found that another tangible contribution of this research is its way of explaining the association between job satisfaction and distributive justice. In fact, several studies have explored and examine the effects of procedural and 
distributive justice on a variety of job outcome like job performance [44]. However, there has remained debate over the comparative significance of distributive and procedural fairness in staff related results. According to the findings of some scholar's distributive impartialities are more vital for employees' satisfaction as compare to the procedural justice to organizational commitment of employees [16]. So the results of this research are in support of previous researchers when explaining job satisfaction in relation to distributive fairness.

However, the results of some researchers McFarline and Sweeney [18], contrary to the research findings, found procedural justice to more important in job related outcomes as compared to distributive justice. Conclusively, the cultural differences of the areas where the research was conducted can be attributed to the reason of comparative role of distributive and procedural justice [45].

\section{Conclusion}

The study was conducted in tight time schedule. As a result, in-depth analysis of some of the factors was left unexplained. Hence, future research on job satisfaction should include several other influential factors. The focus of the study was another limitation. Because of time shortage, data were collected for only one company (National Savings). Hence, findings of this research may be carefully implemented on other companies. With this, it is argued that the current study should be simulated and applied in other organizations both in government and privately owned sectors while considering on the relative effects of procedural justice, distributive justice and employees job satisfaction, and while keeping in view the contentious findings and results related to these factors as originated in this study and also in previous studies situation and settings. This study provides an eye opening insight to various government organizations. The study helps in policy formulation regarding employees and labor management for enhancing their role in economic development. The results of this study also help the academicians in doing further research in the field of performance management.

\section{References}

[1] Kuhlen, R.G. (1963) Needs, Perceived Need Satisfaction Opportunities and Satisfaction with Occupation. Journal of Applied Psychology, 47, 56.

https://doi.org/10.1037/h0045338

[2] Conrad, K.M., Conrad, K.J. and Parker, J.E. (1985) Job Satisfaction among Occupational Health Nurses. Journal of Community Health Nursing, 2, 161-173. https://doi.org/10.1207/s15327655jchn0203 7

[3] Herzberg, F. and Mausner, B. (1959) The Motivation to Work. 2nd Edition, Wiley, New York.

[4] Schmidt, S.W. (2007) The Relationship between Satisfaction with Workplace Training and Overall Job Satisfaction. Human Resource Development Quarterly, 18, 481-498. https://doi.org/10.1002/hrdq.1216

[5] Moynihan, D.P. and Pandey, S.K. (2007) Finding Workable Levers over Work Motivation: Comparing Job Satisfaction, Job Involvement, and Organizational Commitment. Administration \& Society, 39, 803-832. 
https://doi.org/10.1177/0095399707305546

[6] Boyt, T.E., Lusch, R.F. and Naylor, G. (2001) The Role of Professionalism in Determining Job Satisfaction in Professional Services: A Study of Marketing Researchers. Journal of Service Research, 3, 321-330. https://doi.org/10.1177/109467050134005

[7] McAuliffe, E., Manafa, O., Maseko, F., Bowie, C. and White, E. (2009) Understanding Job Satisfaction amongst Mid-Level Cadres in Malawi: The Contribution of Organizational Justice. Reproductive Health Matters, 17, 80-90. https://doi.org/10.1016/S0968-8080(09)33443-6

[8] Roodt, G., Rieger, H. and Sempane, M.E. (2002) Job Satisfaction in Relation to Organizational Culture. SA Journal of Industrial Psychology, 28, 23-30.

[9] Greenberg, J. (1990) Organizational Justice: Yesterday, Today, and Tomorrow. Journal of Management, 16, 399-432. https://doi.org/10.1177/014920639001600208

[10] Konovsky, M.A. (2000) Understanding Procedural Justice and Its Impact on Business Organizations. Journal of Management, 26, 489-511. https://doi.org/10.1177/014920630002600306

[11] Farmer, S., Beehr, T. and Love, K. (2003) Becoming Undercover Police Officers: A Note on Fairness Perceptions, Behavior, and Attitudes. Journal of Organizational Behavior, 24, 373-387. https://doi.org/10.1002/job.196

[12] Constantine, S. (2008) The Self in Procedural Fairness. Social and Personality Psychology Compass, 2, 2107-2124. https://doi.org/10.1111/j.1751-9004.2008.00156.x

[13] Lambert, E. (2003) Justice in Corrections: An Exploratory Study of the Impact of Organizational Justice on Correctional Staff. Journal of Criminal Justice, 31, 155-168.

[14] Greenberg, J. (1990) Looking Fair vs. Being Fair: Managing Impressions of Organizational Justice. Research in Organizational Behavior, 12, 111-157.

[15] Dailey and Haq, Z. (2008) Job Stress among Community Health Workers: A Multi-Method Study from Pakistan. International Journal of Mental Health Systems, 2.

[16] Folger, R. and Konovsky, M. (1989) Effects of Procedural and Distributive Justice on Reactions to Pay Raise Decisions. Academy of Management Journal, 32, 115-130. https://doi.org/10.2307/256422

[17] Huo, Y.J. (1996) Super Ordinate Identification, Subgroup Identification, and Justice Concerns: Is Separatism the Problem; Is Assimilation the Answer? Psychological Science, 7, 40-52. https://doi.org/10.1111/j.1467-9280.1996.tb00664.x

[18] McFarlin, D. and Sweeney (1992) Distributive and Procedural Justice as Predictors of Satisfaction with Personal and Organizational Outcomes. Academy of Management Journal, 35, 626-637. https://doi.org/10.2307/256489

[19] Adams, J. (1963) Towards an Understanding of Inequity. Abnormal and Social Psychology, 67, 422-436. https://doi.org/10.1037/h0040968

[20] Mowday, R.T. and Colwell, K.A. (2003) Employee Reactions to Unfair Outcomes in the Workplace: The Contributions of Adams's Equity Theory to Understanding Work motivation. In: Porter, L.W., Bigley, G.A. and Steers, R.M., Eds., Motivation and Work Behavior, 7th Edition, Irwin/McGraw-Hill, Burr Ridge, 65-82.

[21] Landy, F.J. (1985) Psychology of Work Behavior. I.L. Dorsey Press, Homewood.

[22] Georgellis, Y. and Lange, T. (2007) Participation in Continuous, On-the-Job Training and the Impact on Job Satisfaction: Longitudinal Evidence from the German Labor Market. The International Journal of Human Resource Management, 18, 45-53. https://doi.org/10.1080/09585190701321112 
[23] Melymuka, K. (2004) It's the Opportunities, Stupid. Computer World, 25, 116-127.

[24] Shields, M.A. and Wheatly, S. (2002) Racial Harassment, Job Satisfaction and Intentions to Quit: Evidence from the British Nursing Profession. Economica, 69, 295-326. https://doi.org/10.1111/1468-0335.00284

[25] Tanja, S. (2003) Keeping Teachers Happy: Job Satisfaction among Primary School Teachers in Rural China. International Sociology Association Research Committee on Social Stratification and Mobility, New York University.

[26] Gazioglu, S. and Tansel, A. (2006) Job Satisfaction in Britain: Individual and Job Related Factors. 9th Edition, Rutledge, Part of the Taylor and Francis Group, London.

[27] Jones, K. (2008) Team Training, Job Satisfaction and Workplace Performance in Britain. Discussion Paper 3677.

[28] Blum, R. and Kaplan, J.M. (2000) Network Professionals' Job Satisfaction. Lucent Technologies Network Care, 52, 16-28.

[29] Siddiqui (2003) Continuous Professional Development of a Framework for Medical Doctors in Pakistan. Journal of Pakistan Medical Association, 53, 187-205.

[30] Jaworski, B.J. and Kohli, A.K. (1993) Market Orientation: Antecedents and Consequences. The Journal of Marketing, 57, 53-70. https://doi.org/10.2307/1251854

[31] Boyt, T. (2005) Theoretical Model of the Antecedents and Consequences of Organizational, Workgroup and Professional Esprit de Corps. European Management Journal, 23, 682-701.

[32] Reisel, W.D., Chia, S.L. and Maloles Iii, C.M. (2005) Job Insecurity Spillover to Key Account Management: Negative Effects on Performance, Effectiveness, Adaptiveness, and Esprit de Corps. Journal of Business and Psychology, 19, 483-503. https://doi.org/10.1007/s10869-005-4521-7

[33] Homburg, C. (2002) A Configurational Perspective on Key Account Management. Journal of Marketing, 66, 38-60. https://doi.org/10.1509/jmkg.66.2.38.18471

[34] Dimer, N. (2015) Impact of Sales Team on Job Satisfaction According to Organizational Commitment. International Journal of Finance and Accounting, 4, 195-205.

[35] Hwang, J.I. and Chang, H. (2009) Work Climate Perception and Turn over Intention among Korean Hospital Staff. International Nursing Review, 56, 77-89. https://doi.org/10.1111/j.1466-7657.2008.00641.x

[36] Tirmizi, M.A. (2009) Is It Industry Productive: A Performance Base Investigation of It Sector Firms Operating in Pakistan? International Journal of Business Management, 4, 213-221. https://doi.org/10.5539/ijbm.v4n5p207

[37] Watt, H.M., Richardson, P.W., Klusmann, U., Kunter, M., Beyer, B., Trautwein, U. and Baumert, J. (2012) Motivations for Choosing Teaching as a Career: An International Comparison using the FIT-Choice Scale. Teaching and Teacher Education, 28, 791-805.

[38] Moorman, R.H., Niehoff, B.P. and Organ, D.W. (1993) Treating Employees Fairly and Organizational Citizenship Behavior: Sorting the Effects of Job Satisfaction, Organizational Commitment, and Procedural Justice. Employee Responsibilities and Rights Journal, 6, 209-225. https://doi.org/10.1007/BF01419445

[39] Saunders, M., Lewis, P., Thornhill, A. and Wang, C. (2009) Analysing Qualitative Data. Research Methods for Business Students. 5th Edition, Pearson Education Ltd. Harlow, 480-525.

[40] Hair, J.F., Black, W.C., Babin, B.J., Anderson, R.E. and Tatham, R.L. (1998) Multivariate Data Analysis. Vol. 5, No. 3, 207-219, Prentice Hall, Upper Saddle River. 
[41] Hu, L.T. and Bentler, P.M. (1999) Cutoff Criteria for Fit Indexes in Covariance Structure Analysis: Conventional Criteria versus New Alternatives. Structural Equation Modeling: A Multidisciplinary Journal, 6, 1-55. https://doi.org/10.1080/10705519909540118

[42] Meral, E. (2009) The Impact of Perceived Organizational Ethical Climate on Work Satisfaction. Journal of Business Ethics, 84, 297-311. https://doi.org/10.1007/s10551-008-9709-0

[43] Shields, M.A. and Wheatley Price, S. (2002) The Determinants of Racial Harassment at the Workplace: Evidence from the British Nursing Profession. British Journal of Industrial Relations, 40, 1-21. https://doi.org/10.1111/1467-8543.00220

[44] Cohen-Charash, Y. and Spector, P.E. (2001) The Role of Justice in Organizations: A Meta-Analysis. Organizational Behavior and Human Decision Processes, 86, 278-321. https://doi.org/10.1006/obhd.2001.2958

[45] Pillai, R., Williams, E.S. and Tan, J.J. (2001) Are the Scales Tipped in Favor of Procedural or Distributive Justice? An Investigation the U.S., India, Germany and Hong Kong. International Journal of Conflict Management, 12, 312-332. https://doi.org/10.1108/eb022861

Submit or recommend next manuscript to SCIRP and we will provide best service for you:

Accepting pre-submission inquiries through Email, Facebook, LinkedIn, Twitter, etc. A wide selection of journals (inclusive of 9 subjects, more than 200 journals) Providing 24-hour high-quality service User-friendly online submission system Fair and swift peer-review system Efficient typesetting and proofreading procedure Display of the result of downloads and visits, as well as the number of cited articles Maximum dissemination of your research work

Submit your manuscript at: http://papersubmission.scirp.org/ Orcontact jhrss@scirp.org 